\title{
Anti-HMGCR myopathy may resemble limb-girdle muscular dystrophy
}

Payam Mohassel, MD, * Océane Landon-Cardinal, MD, * A. Reghan Foley, MD, Sandra Donkervoort, MS, CGC, Katherine S. Pak, MD, Colleen Wahl, FNP, DNP, Robert T. Shebert, MD, Amy Harper, MD, Pierre Fequiere, MD, Matthew Meriggioli, MD, Camilo Toro, MD, Daniel Drachman, MD, Yves Allenbach, MD, PhD, Olivier Benveniste, MD, PhD, Anthony Béhin, MD, Bruno Eymard, MD, PhD, Pascal Lafôret, MD, PhD, Tanya Stojkovic, MD, Andrew L. Mammen, MD, PhD, and Carsten G. Bönnemann, MD

Neurol Neuroimmunol Neuroinflamm 2019;6:e523. doi:10.1212/NXI.0000000000000523

\section{Abstract}

\section{Objective}

To determine the prevalence and clinical features of anti-HMGCR myopathy among patients with presumed limb-girdle muscular dystrophy (LGMD) in whom genetic testing has failed to elucidate causative mutations.

\section{Methods}

Patients with presumed LGMD and unrevealing genetic testing were selected based on a few clinico-pathologic features and tested for anti-HMGCR autoantibodies $(n=11)$. These clinicopathologic features are peak creatine kinase (CK) greater than 1,000 IU/L and at least 3 of the following features: (1) limb-girdle pattern of weakness, (2) selective involvement of posterior thigh on clinical examination or muscle imaging, (3) dystrophic changes on muscle biopsy, and (4) no family history of muscular dystrophy.

\section{Results}

Six patients tested positive for anti-HMGCR autoantibodies. In 4, there was a presymptomatic phase, lasting as long as 10 years, characterized by elevated CK levels without weakness. Muscle biopsies revealed variable degrees of a dystrophic pathology without prominent inflammation. In an independent cohort of patients with anti-HMGCR myopathy, 17 of 51 ( 33\%) patients were initially presumed to have a form of LGMD based on clinico-pathologic features but were ultimately found to have anti-HMGCR myopathy. Most of these patients responded favorably to immunomodulatory therapies, evidenced by reduction of $\mathrm{CK}$ levels and improved strength.

\section{Conclusions}

Anti-HMGCR myopathy can resemble LGMD. Diagnosis of patients with a LGMD-like presentation of anti-HMGCR myopathy is critical because these patients may respond favorably to immunotherapy, especially those with shorter disease duration.
Correspondence

Dr. Bönnemann

carsten.bonnemann@nih.gov

\footnotetext{
*These authors have equally contributed to the manuscript.
}

From the National Institutes of Health (P.M., A.R.F., S.D., C.G.B.), NINDS, NNDCS, Bethesda, MD; Department of Internal Medicine and Clinical Immunology (O.L.-C., Y.A., O.B.), Sorbonne Universités, University Pierre et Marie et Curie, APHP, Hôpital Pitié-Salpêtrière, Paris, France; National Institutes of Health (K.P., A.L.M.), NIAMS; National Institutes of Health (C.W., C.T.), NHGRI, UDP, Bethesda, MD; Department of Neurology (R.T.S.), University of Miami, Miami, FL; Department of Neurology (A.H.), Virginia Commonwealth University, Richmond, VA; Division of Pediatric Neurology (P.F.), Department of Pediatrics, University of Alabama, Birmingham; Department of Neurological Sciences (M.M.), Rush University Medical Center, Chicago, IL; Department of Neurology (D.D., A.L.M.), Department of Medicine (A.L.M.), Johns Hopkins University, Baltimore, MD; AP-HP (A.B., B.E., T.S.), G-H PitiéSalpêtrière, Institut de Myologie, Paris; and Neurology Department (P.L.), Raymond Poincaré Hospital, Garches, APHP and INSERM U1179, END-ICAP, Versailles Saint-Quentin-enYvelines University, Montigny-le-Bretonneux, France.

Funding information and disclosures are provided at the end of the article. Full disclosure form information provided by the authors is available with the full text of this article at Neurology.org/NN. 


\section{Glossary}

ALBIA = addressable laser bead immunoassay; CK = creatine kinase; FSHD = facioscapulohumeral dystrophy; IVIg = intravenous immunoglobulin; LGMD = limb-girdle muscular dystrophy; MRC = Medical Research Council; NGS = nextgeneration sequencing; PAS = periodic acid Schiff; STIR = short tau inversion recovery; WES = whole exome sequencing; WGS $=$ whole genome sequencing.

Limb-girdle muscular dystrophies (LGMDs) encompass a heterogeneous group of hereditary, degenerative myopathies that pose a major diagnostic challenge. Current genomics approaches do not identify a definitive genetic abnormality in $40 \%-60 \%$ of these patients (reviewed here ${ }^{1}$ ). Although most patients presenting with chronic, slowly progressive myopathies will be presumed to have a hereditary myopathy, and in most cases an LGMD, autoimmune myopathies can also present with a similar chronic disease course (reviewed here ${ }^{2}$ ).

Autoimmune anti-HMGCR (3-hydroxy-3-methylglutarylcoenzyme A reductase) myopathy typically has an acute or subacute disease course in older adults with a history of statin exposure $^{3}$ and is defined by the presence of serum antiHMGCR autoantibodies. ${ }^{4}$ Yet, young adults and children without statin exposure may also develop anti-HMGCR myopathy, some of whom are anecdotally reported to present with a chronic, LGMD-like phenotype. ${ }^{5-11}$ Thus, we hypothesized that some patients with presumed LGMD, specifically those in whom genetic testing has failed to elucidate causative mutations (i.e., "unrevealing genetic testing"), may actually have anti-HMGCR myopathy. We use the term "antiHMGCR myopathy" to refer to a myopathy associated with anti-HMGCR autoantibodies. ${ }^{12}$

Using a few clinico-pathologic criteria, followed by autoantibody testing, we screened our cohort of patients with clinically suspected LGMD and unrevealing genetic testing and identified 6 patients ( 1 previously reported ${ }^{6}$ ) with anti-HMGCR myopathy. Furthermore, in a separate cohort, 17 patients with antiHMGCR myopathy $(\sim 33 \%)$ were identified who were initially presumed to have LGMD based on a chronic disease course and clinico-pathologic features. A favorable treatment response could be documented for most patients. In this study, we expand the clinical spectrum of anti-HMGCR myopathy to include a chronic phenotype closely resembling LGMD, with important diagnostic repercussions given the treatment implications.

\section{Methods}

\section{Standard protocol approvals, registrations, and patient consents}

The National Institutes of Health (NIH) patients were evaluated under research protocols approved by the Institutional Review Boards of National Institute of Neurological Disorders and Stroke (NINDS) (protocol 12-N-0095) or the Undiagnosed Diseases Program, National Human Genome Research Institute (NHGRI) (protocol 15-HG-0130) between January 2014 and December 2016. Written informed consent and/or assent (for minor patients) was obtained from each participant in the study.

\section{Clinico-pathologic criteria for patient selection}

Patients with presumed hereditary myopathy with unrevealing genetic testing $(n=128)$ were referred to the NIH for additional genetic and diagnostic evaluation. All patients had nextgeneration sequencing-based LGMD panel testing through commercial laboratories before referral to the NIH. The patients were included for anti-HMGCR autoantibody testing if they had elevated creatine kinase (CK) (peak level $>1,000$ $\mathrm{U} / \mathrm{L}$ ) and met at least 3 of the following criteria: (1) limbgirdle pattern of weakness, (2) relatively more prominent involvement of the posterior thigh compartment compared with anterior thigh on manual muscle testing or imaging, (3) chronic myopathic changes as well as myofiber degeneration and regeneration on muscle biopsy, and (4) no family history of muscular dystrophy. These features were purposefully chosen to be compatible with both LGMD and anti-HMGCR myopathy. ${ }^{6,9,13,14}$ Most patients had variable CK levels; thus, we included them in the study if they had at least 1 documented $\mathrm{CK}$ value greater than $1,000 \mathrm{U} / \mathrm{L}$.

\section{Patient evaluation and testing}

Patients underwent clinical evaluation (history and neuromuscular examination), muscle MRI, muscle ultrasound, blood laboratory testing (CK and human leukocyte antigen [HLA] subtype testing), genetic testing, pulmonary function testing, and echocardiogram. DNA, blood samples, and tissue were obtained based on standard procedures. Testing for autoantibodies against HMGCR were performed using Clinical Laboratory Improvement Amendments-certified laboratories (RDL, CA or ARUP, UT). All positive results were confirmed using an immunoprecipitation assay as previously described. ${ }^{4}$ The patients reported their overall symptoms and muscle strength using a general clinic questionnaire at each visit. Manual muscle testing using the Medical Research Council (MRC) grade was performed at each visit by at least 2 different neuromuscular neurologists. Discrepant ratings were consolidated at each visit at the bedside. Pediatric patients (P1 and P2) also underwent timed tests (e.g., getting up from supine to the standing position). Some patients also underwent serial handheld dynamometry (P3 and P4) at follow-up visits.

The patients who tested positive for anti-HMGCR autoantibodies $(n=6 / 11)$ were treated with immunosuppressive therapies and prospectively followed. The patients and the clinicians were not blinded to the treatments. 


\section{Muscle MRI and ultrasound}

Muscle MRI was performed using conventional T1-weighted spin echo and short tau inversion recovery (STIR) of the lower extremities on a 3.0T Achieva Phillips, 3.0T Verio Siemens, or 1.5T Aera Siemens system. Noncontrast images were obtained from the pelvis, thighs, and lower legs in the axial plain. Slices were 5-10 mm thick. The gap between slices was $8-10 \mathrm{~mm}$ thick. Muscle ultrasound was performed using an upgraded Siemens S2000 with a $15 \mathrm{MHz}$ linear probe.

\section{Molecular genetic testing}

Of the anti-HMGCR-positive patients $(\mathrm{n}=6), 3$ patients (P2 and her mother, $\mathrm{P} 4$ and his parents, $\mathrm{P} 5$ and his parents and unaffected sibling) had research-based whole exome sequencing (WES) testing at the NIH Intramural Sequencing Center using the SeqCap EZ Exome + UTR Library Kit (Roche, Nimblegen) and Illumina HiSeq2500 sequencing instruments. One patient (P6) underwent clinical WES (Baylor University) and whole genome sequencing (WGS) (HudsonAlpha, Huntsville, AL). All anti-HMGCR negative patients $(n=5)$ underwent WES at the NIH. Filtering of variants was carried out for 4 different segregation scenarios (de novo, recessive homozygous, recessive compound heterozygous, and isolated singleton proband) using a customized SQL script with the following parameters: minimum allele frequency less than $0.5 \%$ in the Exome Aggregate Consortium, National Heart, Lung, and Blood Institute (NHLBI) Exome Variant Server databases, and in the laboratory's aggregate exome variant database with 587 exomes; Combined Annotation Dependent Depletion score greater than 20; and coverage greater than 10 reads.

\section{Validation cohort patients}

The patients in the validation cohort were evaluated at the National Referral Center for rare neuromuscular diseases at the Pitié-Salpêtrière University Hospital (Paris, France) between 2000 and 2017. All patients with anti-HMGCR myopathy who were initially clinically suspected of having LGMD were identified. These patients had been evaluated as part of routine clinical visits in the outpatient clinic or during inpatient hospitalization at the Institute of Myology or internal medicine ward. Medical records were reviewed to assess clinical features, serum CK levels, muscle biopsy findings, electrodiagnostic studies, muscle MRI, and response to immunosuppressive therapies. Molecular and/or genetic testing for LGMD or other common hereditary myopathies was reviewed. Anti-HMGCR antibodies were identified using ELISA (Inova Diagnostics, Inc, San Diego, CA) or addressable laser bead immunoassay (ALBIA) (Rouen, France). ${ }^{15}$ All of these patients also had a dot blot myositis profile (including anti-Jo1, -PL7, -PL12, -Pm/Scl, -Scl70, -Ku, -SRP, and -Mi-2 autoantibodies) using line immunoassays (EuroimmunGermany or D-Tek-Belgium).

\section{Data availability}

Additional de-identified clinical data pertaining to this study are available on request from the authors.

\section{Results}

Identification and characterization of patients Eleven patients met the clinico-pathologic entry criteria as described in the Methods section, 6 of whom ( 1 previously reported $\left.^{6}\right)$ had positive anti-HMGCR autoantibodies, with titers 2-10 times the upper limit of normal. None of the 6 patients with anti-HMGCR myopathy tested positive for antiSRP autoantibodies or other myositis-specific autoantibodies when tested. The summary of relevant clinical findings in the patients with anti-HMGCR autoantibodies is provided in table 1 . In contrast to classic cases of anti-HMGCR myopathy, the disease course was indolent in these patients. Elevated $\mathrm{CK}$, aspartate transaminase, or alanine transaminase (presumably originating from muscle), often preceded the onset of overt muscle weakness, in some cases by more than 10 years. None of the patients took statin drugs, but 1 patient (P6) took mushroom supplements (a natural source of statins) before developing muscle weakness.

A predominantly proximal pattern of muscle weakness was notable in all patients with near-complete sparing of distal muscles (e.g., anterior tibial group). Lower extremity weakness preceded upper extremity weakness and was more severe. Moderate to severe scapular winging was noted in 5 of the 6 patients, without selective involvement of scapular fixators. At the time of presentation, P1-P4 remained independently ambulatory. P5 relied on the assistance of a cane for outdoor ambulation, whereas P6 relied on a motorized wheelchair. Neck flexion, arm abduction (deltoid), elbow flexion, and to a lesser degree elbow extension were affected in the upper extremities. In the lower extremities, hip flexion, hip adduction, hip extension, hip abduction, knee flexion, and to a lesser degree knee extension were most commonly affected. Extraocular and facial muscles were spared.

\section{Muscle imaging}

Muscle MRI of the lower extremities showed a common pattern of involvement. Patients with shorter duration of disease showed minimal changes in $\mathrm{T} 1$ signal in the thighs or lower legs, whereas those with longer duration of disease showed T1 hyperintensity in paraspinal muscles, glutei, hamstrings, and adductors with variable involvement and atrophy of the quadriceps muscles. The gracilis muscle was relatively preserved (figure 1, A). In the lower leg, the pattern was more variable, with the medial gastrocnemius showing increased $\mathrm{T} 1$ signal in a heterogeneous and patchy distribution (3 of 6 patients). The tibialis anterior was relatively preserved (figure 1, B). In addition, thigh and lower leg muscles had hyperintense STIR signal with a heterogeneous and patchy distribution (figure 1, C). STIR signal hyperintensity was not limited to areas of T1 hyperintensity, suggestive of ongoing disease activity.

Muscle ultrasound showed an overall patchy and granular pattern of increased echogenicity in the patients with a shorter disease duration and more diffusely echodense muscles in those with longer disease duration. In the upper extremities, ultrasound 
Table 1 Clinical characteristics of NIH patients

\begin{tabular}{|c|c|c|c|c|c|c|}
\hline & Patient 1 & Patient 2 & Patient 3 & Patient 4 & Patient 5 & Patient 6 \\
\hline Sex & M & $\mathrm{F}$ & $\mathrm{F}$ & M & M & $\mathrm{F}$ \\
\hline Age (y) & 13.5 & 12 & 30 & 36 & 41 & 48 \\
\hline First sign, age (y) & $\begin{array}{l}\text { Decline in } \\
\text { running speed, } \\
10\end{array}$ & $\begin{array}{l}\text { Could not jump } \\
\text { or run, } 8^{\text {a }}\end{array}$ & Elevated CK, 19 & $\begin{array}{l}\text { Difficulty rising from the } \\
\text { floor, } 20^{\mathrm{b}}\end{array}$ & $\begin{array}{l}\text { Elevated LFTs, } \\
21\end{array}$ & $\begin{array}{l}\text { Dysphagia and } \\
\text { elevated CK, } 25\end{array}$ \\
\hline $\begin{array}{l}\text { Disease } \\
\text { duration }(y)\end{array}$ & 3.5 & $4^{a}$ & 11 & $16^{\mathrm{b}}$ & 20 & 23 \\
\hline CK (IU/L) & $7,000-9,000$ & $13,000-23,000$ & $3,000-10,000$ & $350-1,200$ & 5,000 & $3,000-11,000$ \\
\hline EMG/NCS & ND & $\begin{array}{l}\text { Irritable } \\
\text { myopathy }\end{array}$ & $\begin{array}{l}\text { Irritable } \\
\text { myopathy }\end{array}$ & $\begin{array}{l}\text { Irritable } \\
\text { myopathy }\end{array}$ & $\begin{array}{l}\text { Irritable } \\
\text { myopathy }\end{array}$ & $\begin{array}{l}\text { Irritable } \\
\text { myopathy }\end{array}$ \\
\hline $\begin{array}{l}\text { Genetic and } \\
\text { molecular } \\
\text { testing }\end{array}$ & $\begin{array}{l}\text { Extended } \\
\text { neuromuscular } \\
\text { panel }\end{array}$ & $\begin{array}{l}\text { LGMD panel and } \\
\text { WES }\end{array}$ & $\begin{array}{l}\text { LGMD panel and } \\
\text { GAA dried blood } \\
\text { test }\end{array}$ & $\begin{array}{l}\text { LGMD panel; FSHD; DM2; } \\
\text { and WES }\end{array}$ & $\begin{array}{l}\text { LGMD panel; } \\
\text { WES; and GAA } \\
\text { dried blood } \\
\text { test }\end{array}$ & $\begin{array}{l}\text { LGMD panel; MFM } \\
\text { panel; WES; and WGS }\end{array}$ \\
\hline HLA-DRB1 & 07:01; 15:01 & $11: 01 ; 11: 02$ & $11: 01 ; 11: 03$ & $11: 01 ; 11: 04$ & 01 or 15 (Amb) & 07:01; 13:01 \\
\hline Echocardiogram & Normal & Normal & Normal & Normal & Normal & Normal \\
\hline PFT & FVC 3.08 L (81\%) & FVC 2.00 L (71\%) & FVC 2.49 L (78\%) & FVC 4.64 L (77\%) & FVC 3.69 L (74\%) & FVC 2.80 L (84\%) \\
\hline $\begin{array}{l}\text { Other } \\
\text { comments }\end{array}$ & $\begin{array}{l}\text { Linear morphea } \\
\text { scleroderma }\end{array}$ & $\begin{array}{l}\text { Exotropia noted } \\
\text { in early } \\
\text { childhood }\end{array}$ & $\begin{array}{l}\text { Dural sinus } \\
\text { thrombosis while } \\
\text { on oral } \\
\text { contraceptive } \\
\text { pills }\end{array}$ & $\begin{array}{l}\text { Liver biopsy showed mild } \\
\text { fatty liver disease; } \\
\text { obstructive sleep apnea } \\
\text { on BiPAP }\end{array}$ & $\begin{array}{l}\text { Liver biopsy with } \\
\text { normal results }\end{array}$ & $\begin{array}{l}\text { Took mushroom } \\
\text { supplements in her } \\
20 \text {; had bilateral } \\
\text { calf herniation at } 13 \mathrm{y}\end{array}$ \\
\hline
\end{tabular}

Abbreviations: $\mathrm{Amb}=$ ambiguous; $\mathrm{CK}=$ creatine kinase; $\mathrm{DM} 2=$ myotonic dystrophy type 2; FSHD = facioscapulohumeral muscular dystrophy; FVC = forced vital capacity; GAA = glucosidase alpha acid; LFT = liver function test; LGMD = limb-girdle muscular dystrophy; MFM = myofibrillar myopathy; ND = not done; PFT = pulmonary function test; WES = whole exome sequencing; WGS = whole genome sequencing.

${ }^{a}$ The patient was never able to ride a bike independently (normally achieved by age 5 years or earlier) or play with monkey bars in the playground.

${ }^{\mathrm{b}}$ The patient was never able to perform a push-up or pull-up and was a slow runner in his teens.

highlighted selective involvement of certain muscle groups (e.g., biceps more than triceps) (figure 2).

\section{Muscle histology}

Severe myofiber atrophy, fiber size variability, and increased internalized nuclei were nearly universal findings (figure 3 ). Most biopsies included other chronic myopathic features such as splitting myofibers and increased endomysial fibrosis. Myofiber degeneration/necrosis and regeneration was a variable feature. Some biopsies showed many degenerating/ necrotic myofibers, some actively undergoing myophagocytosis (P2), whereas others had only a single degenerating fiber (P4). A few biopsies showed a single or 2 small foci of chronic perivascular inflammation composed of macrophages and CD3-positive T cells. None of the biopsies showed prominent primary inflammation-nonnecrotic myofibers surrounded and/or invaded by chronic inflammatory cells. MHC-1 was increased in degenerating fibers and rare nonnecrotic fibers, but it appeared normal or only minimally increased in other areas. None of the patients had diagnostic changes in known LGMD proteins based on immunostaining.

A few additional nonspecific histologic findings were noted: muscle biopsy of $\mathrm{P} 6$ had inclusions in some muscle fibers that stained positive with periodic acid Schiff (PAS) stain, as well as with desmin, myotilin, and $\alpha \beta$-crystallin immunostains. These PAS-positive inclusions were $\alpha$-amylase sensitive and did not stain with adenosine triphosphatase or oxidative stains, suggesting that they do not contain polyglucosan bodies, myosin, or intermyofibrillar material. A single subsarcolemmal redrimmed vacuole was noted in the muscle biopsy of P4.

\section{Genetic testing}

All anti-HMGCR-positive patients $(\mathrm{n}=6)$ had undergone commercial genetic testing for common LGMDs using nextgeneration sequencing (NGS) panels before referral to the $\mathrm{NIH}$ (table 1). Because of the presence of asymmetric findings and scapular winging, 2 patients were tested for facioscapulohumeral dystrophy (FSHD). Other patients lacked typical features of FSHD and were not directly tested. Because of the preponderance of internalized nuclei in P4, myotonic dystrophy type 2 was also considered and ruled out by direct testing. Four patients also underwent WES, 3 at the NIH (P2, P4, and P5) and one through a commercial laboratory (P6). Because of the presence of myofibrillar inclusions in P6's muscle biopsy and a suspicion for an underlying myofibrillar myopathy, she also underwent WGS. None of the patients had pathogenically relevant variants (excluding benign variants) that matched familial segregation studies or mode of inheritance of the disease associated with the gene in question. 


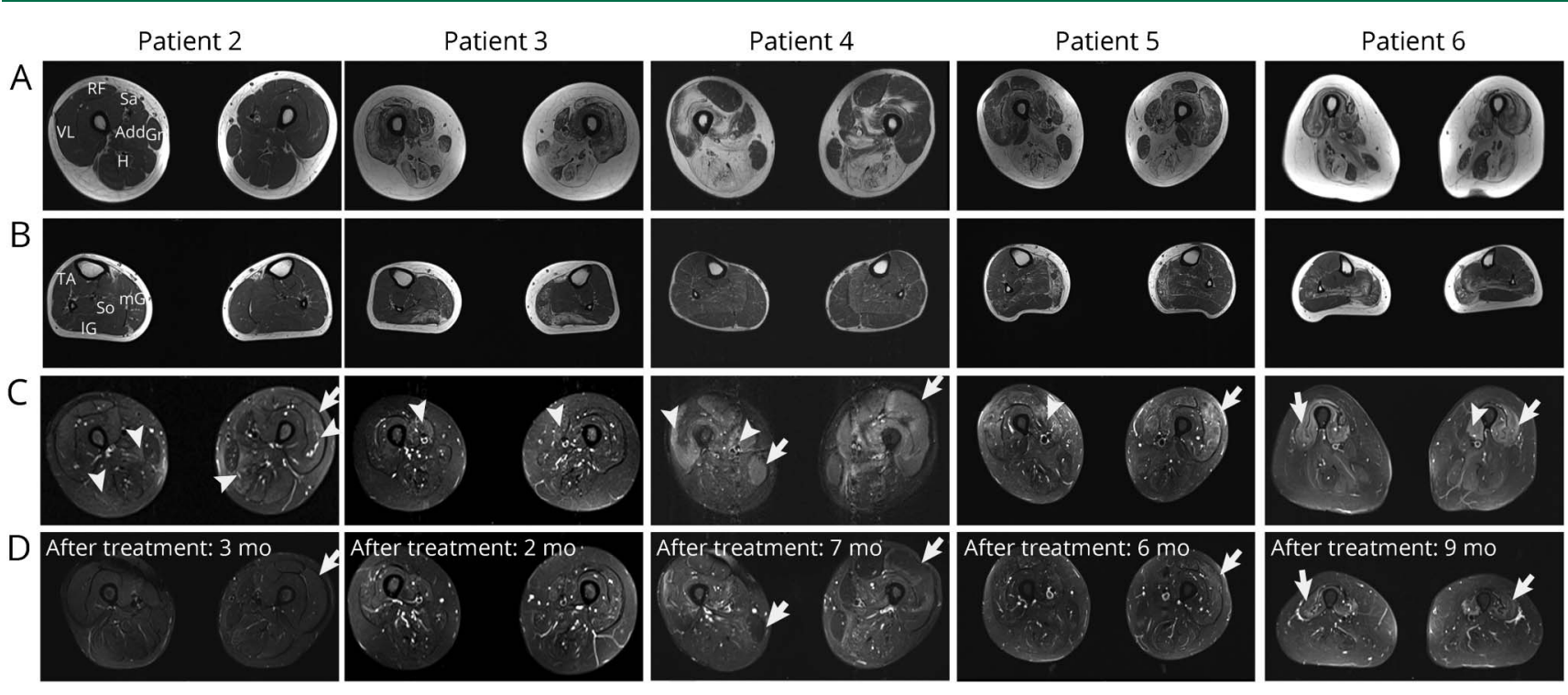

Muscle MRI showing increased T1 hyperintensity in the hamstrings, adductors, and variably in quadriceps muscles. Gracillis muscle appears relatively preserved (panel A). Medial gastrocnemius is variably involved in the lower leg (panel B). STIR signal is increased predominantly in the hamstrings, quadriceps, and adductor muscles (C, arrowheads). After treatment, STIR signal is decreased in most patients, especially those evaluated later after initiation of treatment ( $\mathrm{D}$, arrows). VL = vastus lateralis; RF = rectus femoris; $\mathrm{Sa}=$ sartorius; $\mathrm{Add}=$ adductor magnus; $\mathrm{Gr}=$ gracilis; $\mathrm{H}=\mathrm{hamstrings;} \mathrm{TA}=$ tibialis anterior; So = soleus; $\mathrm{mG}$ = medial gastrocnemius; IG = lateral gastrocnemius .

Most ( $\sim 70 \%)$ adult patients with anti-HMGCR myopathy possess the HLA-DRB1*11:01 allele, ${ }^{16,17}$ whereas HLA $\mathrm{DRB} 1^{*}$ 07:01 is recently reported in several pediatric patients with anti-HMGCR myopathy. ${ }^{7}$ We tested these 6 patients for the presence of either allele. All but 1 patient had the HLA$\mathrm{DRB}^{*} 07: 01$ or 11:01 allele (table 1 ).

\section{Follow-up after treatment}

After confirmation of anti-HMGCR myopathy, all patients $(\mathrm{n}=$ 6) were treated with IV immunoglobulins (IVIg) and seen in follow-up at the NIH. Steroids (methylprednisolone, $750 \mathrm{mg}$ every 3 weeks) were added to P6's regimen after 4 months of IVIg therapy. The patients were re-examined, CK was remeasured, and a muscle MRI was repeated. Most patients reported improved function and improved muscle strength. Manual muscle testing using MRC grading or handheld dynamometry showed improvement in muscle strength, at least in select muscle groups (table 2). P2 also showed significant improvement in timed rise from the floor, a commonly used outcome measure in pediatric muscular dystrophy. ${ }^{18}$ All patients showed a marked reduction in CK levels. Most patients also had a marked reduction in muscle MRI STIR signal intensity (figure $1, D)$. The pediatric patients $(n=2$; mean age 12 years $)$, who had a shorter duration of symptoms before initiation of therapy, demonstrated the most dramatic improvements in strength and function to normal or near-normal levels (table 2).

Figure 2 Muscle ultrasound

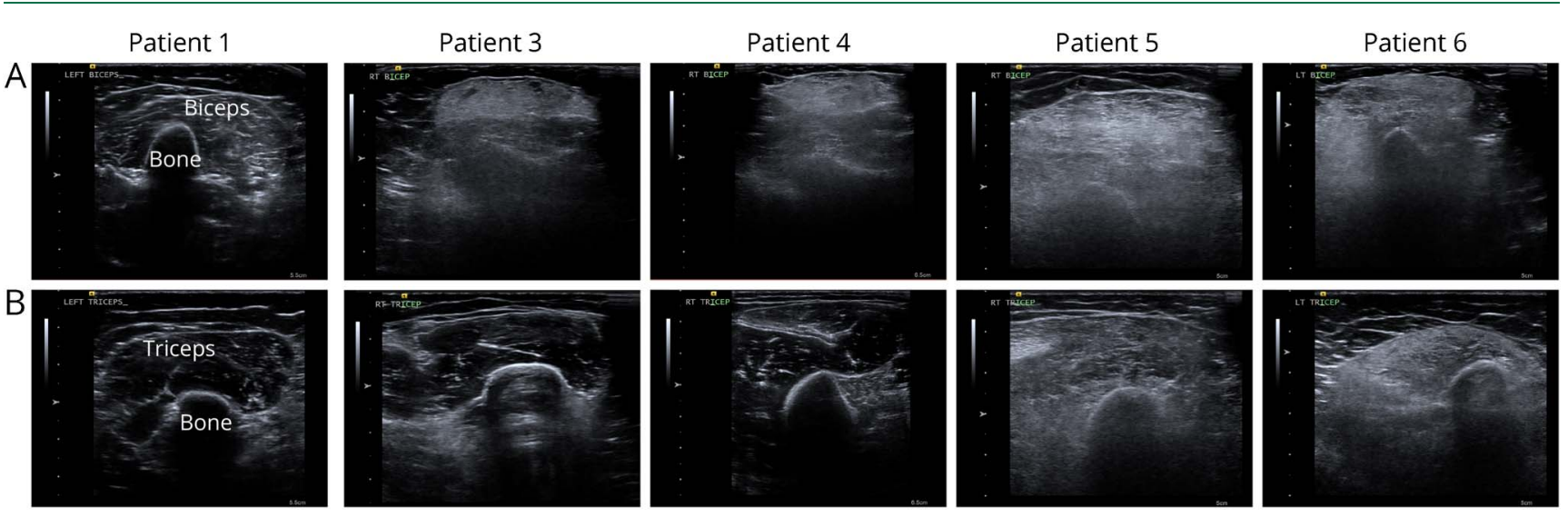

Muscle ultrasound showing selective involvement and increased echogenicity in the biceps muscle (row A) when compared with the triceps muscle (row B). 


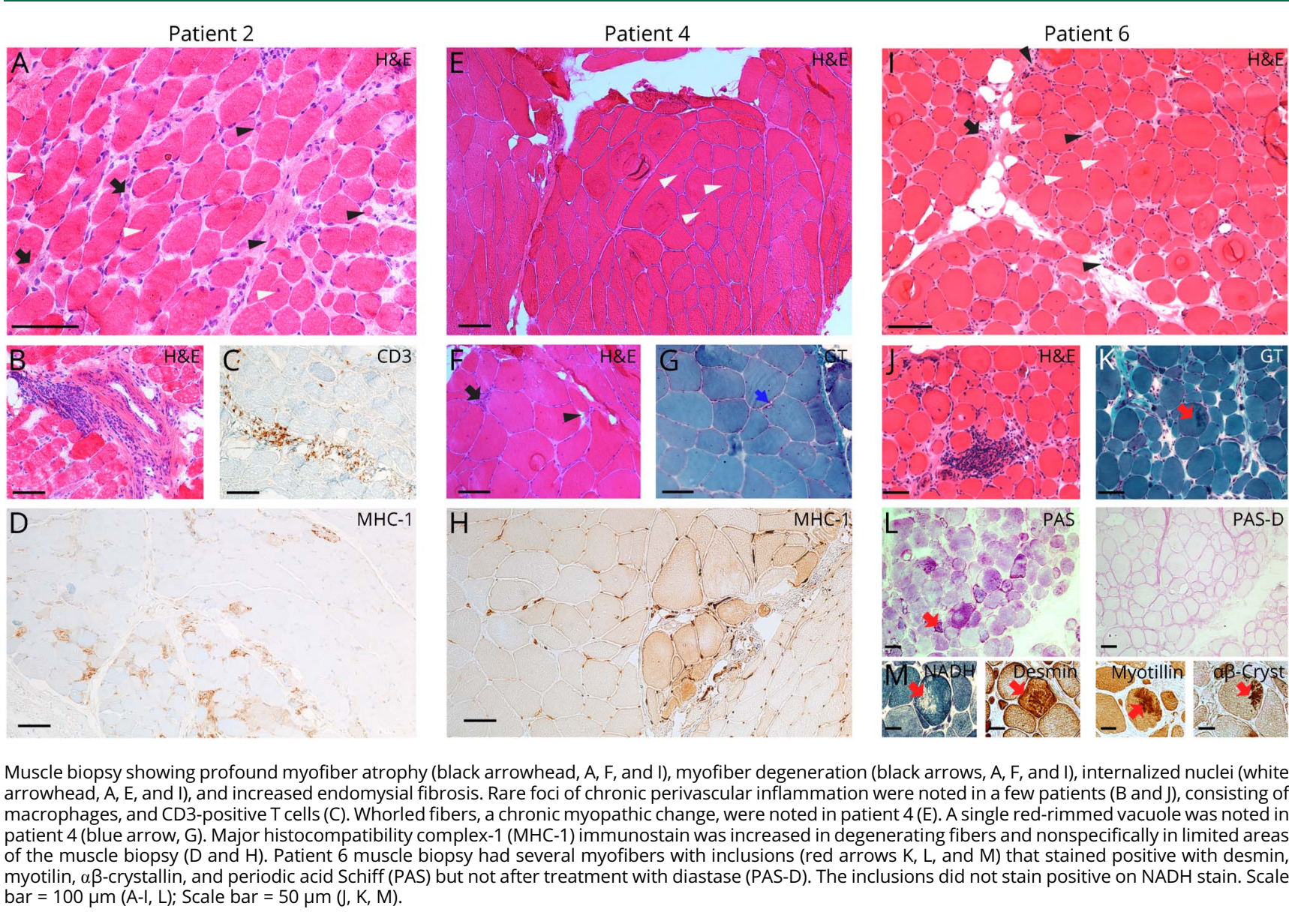

After 1 year of follow-up, all patients remain on immunosuppression, and most continue to report improvement or stabilization of weakness; none report worsening weakness. P6 is able to ambulate with a walker for the first time in 2 years. $\mathrm{P} 2$ reports regaining the ability to run. P1 attempted to lengthen the treatment interval of IVIg to every 5 weeks and developed elevated $\mathrm{CK}$ levels $(\sim 1,100 \mathrm{U} / \mathrm{L})$. A few months later, he noted a decline in athletic performance. Two months after returning to

Table 2 Response to treatment in patients with limb-girdle phenotype of anti-HMGCR myopathy

\begin{tabular}{|c|c|c|c|c|c|c|}
\hline & Patient 1 & Patient 2 & Patient 3 & Patient 4 & Patient 5 & Patient 6 \\
\hline Treatment & $\begin{array}{l}\mathrm{IVIg} \sim 1.5 \mathrm{~g} / \\
\mathrm{kg} \text { monthly }\end{array}$ & $\begin{array}{l}\mathrm{IVIg} \sim 2 \mathrm{~g} / \mathrm{kg} \\
\text { monthly }\end{array}$ & $\begin{array}{l}\mathrm{IVlg} \sim 2 \mathrm{~g} / \mathrm{kg} \\
\text { monthly }\end{array}$ & $\begin{array}{l}\mathrm{IVIg} \sim 2 \mathrm{~g} / \mathrm{kg} \\
\text { monthly }\end{array}$ & IVIg 2g/kg monthly & $\begin{array}{l}\mathrm{IVIg} \sim 1.5 \mathrm{~g} / \mathrm{kg}+750 \mathrm{mg} \\
\text { methylprednisolone every } 3 \mathrm{wk}\end{array}$ \\
\hline $\begin{array}{l}\text { Interval before } \\
\text { re-evaluation }\end{array}$ & $30 \mathrm{mo}$ & $18 \mathrm{mo}$ & $18 \mathrm{mo}$ & $7 \mathrm{mo}$ & $6 \mathrm{mo}$ & $9 \mathrm{mo}$ \\
\hline $\begin{array}{l}\text { Reported } \\
\text { functional } \\
\text { improvement }\end{array}$ & $\begin{array}{l}\text { Running } \\
\text { speed }\end{array}$ & $\begin{array}{l}\text { Walking } \\
\text { speed }\end{array}$ & $\begin{array}{l}\text { Walking } \\
\text { speed }\end{array}$ & $\begin{array}{l}\text { Rising from the } \\
\text { floor }\end{array}$ & $\begin{array}{l}\text { Walking speed and } \\
\text { raising arms above the } \\
\text { head }\end{array}$ & $\begin{array}{l}\text { Rolling over in the bed, gait stability, } \\
\text { walk with a walker, and raising arms }\end{array}$ \\
\hline $\begin{array}{l}\text { Manual muscle } \\
\text { testing }\end{array}$ & $\begin{array}{l}\text { Improved } \\
\text { to normal }\end{array}$ & Improved & Improved & $\begin{array}{l}\text { Stable/improved } \\
\text { in select muscles } \\
\text { only }\end{array}$ & $\begin{array}{l}\text { Stable/improved in } \\
\text { select muscles only }\end{array}$ & $\begin{array}{l}\text { Stable/improved in select muscles } \\
\text { only }\end{array}$ \\
\hline $\begin{array}{l}\text { CK before/after } \\
\text { treatment (IU/L) }\end{array}$ & $3,789 / 509$ & $13,270 / 6,205$ & $3,876 / 971$ & $351 / 166$ & $4,993 / 450$ & $3,222 / 296$ \\
\hline MRI STIR & Normalized & Normalized & Unchanged & Improved & Improved & Improved \\
\hline
\end{tabular}

Abbreviations: $\mathrm{AA}=$ arm abduction; $\mathrm{CK}=$ creatine kinase; $\mathrm{EF}=$ elbow flexion; $\mathrm{HA}=$ hip abduction; $\mathrm{HE}=$ hip extension; $\mathrm{HF}=$ hip flexion; $\mathrm{IVIg}=$ intravenous immunoglobulin; $\mathrm{KE}=$ knee extension; STIR = short tau inversion recovery; $\mathrm{WE}=$ wrist extension; $\mathrm{WF}$ = wrist flexion. 
his previous IVIg schedule (every 4 weeks), his CK has decreased $(\sim 800 \mathrm{U} / \mathrm{L})$, and his athletic performance has improved.

\section{Validation cohort}

We subsequently investigated another patient cohort in a large neuromuscular referral center in France. We asked the reverse question: how prevalent is a chronic, LGMD-like presentation among patients with already-established antiHMGCR myopathy? Among 51 anti-HMGCR myopathy cases examined, 17 patients $(\sim 33 \%)$ were initially suspected to have LGMD based on clinical findings and muscle biopsy criteria, all without genetic diagnostic confirmation. All 17 patients underwent specific molecular or genetic testing for LGMD (including dystrophin $[D M D]$, dysferlin [DYSF], sarcoglycans [SGCA, SGCB, SGCG, and $S G C D$ ], calpain-3 [CAPN3], caveolin-3 [CAV3], anoctamin 5 [ANO5], fukutinrelated protein $[F K R P])$, or other hereditary myopathies such as acid maltase deficiency or type 2 myotonic dystrophy. These 17 patients had a clinical presentation and course of disease evolution similar to the initial cohort (table 3). Most patients had a prolonged disease course that initially presented with asymptomatic or oligosymptomatic hyperCKemia, exercise intolerance, or myalgia (table e-1, links.lww. com/NXI/A90). A third of the patients had scapular winging. In those who had individual muscle group strength data available, the majority $(\sim 62 \%)$ had weakness of knee flexion greater than extension; however, 3 (23\%) had knee extension greater then flexion weakness, whereas there was no difference in $2(15 \%)$ patients. All patients displayed markedly elevated CK levels (mean: 6,580 U/L). Muscle histologic findings included myofiber degeneration and regeneration in

Table 3 Clinical characteristics and response to treatment in the validation cohort

\begin{tabular}{|c|c|}
\hline Age (y); mean & $17-66 ; 40$ \\
\hline Disease duration (y); mean & $1-26 ; 11$ \\
\hline Female & $N=14 / 17(82 \%)$ \\
\hline Limb-girdle weakness & $N=16 / 17(94 \%)$ \\
\hline Scapular winging & $N=6 / 17(35 \%)$ \\
\hline $\begin{array}{l}\text { Knee flexion weakness > knee extension } \\
\text { weakness }\end{array}$ & $N=8 / 13(62 \%)$ \\
\hline Peak CK (U/L); mean & $1,200-17,000 ; 6,580$ \\
\hline Myopathic EMG & $N=17 / 17(100 \%)$ \\
\hline Muscle biopsy findings of chronic myopathy & $N=15 / 17(88 \%)$ \\
\hline Statin drug exposure & $N=4 / 17(24 \%)$ \\
\hline Improved strength after immunotherapy & $N=11 / 13(85 \%)$ \\
\hline CK after treatment (U/L); mean ${ }^{a}$ & $30-600 ; 201$ \\
\hline IVIg at the last follow-up & $N=10 / 13(77 \%)$ \\
\hline
\end{tabular}

Abbreviations: $\mathrm{CK}=$ creatine kinase; $\mathrm{EMG}=$ electromyography; IVIg = intravenous immunoglobulin.

a Checked in 13 patients. all patients and chronic myopathic changes in most patients. Most patients were treated with various regimens and immunosuppressive agents, although a few patients declined treatment, typically those with only mild weakness or asymptomatic hyperCKemia. Only a minority of these patients had exposure to statins $(\sim 24 \%)$. Overall, most patients treated with immunosuppressant therapies demonstrated improved muscle strength and functional capacity, especially those with relatively shorter disease duration (table e-2, links.lww.com/NXI/A91). Some patients with prolonged disease duration and evidence of severe muscle damage documented on muscle MRI did not show clear improvements in muscle strength testing. However, a decline in CK levels was seen in all treated patients. At the last follow-up, most of these patients (10 of 13; 77\%) were still receiving IVIg either as monotherapy or in combination with another immunosuppressant.

\section{Discussion}

We have characterized in detail a less recognized yet clinically important phenotype of anti-HMGCR myopathy that mimics LGMD. In our cohort of patients with clinically suspected LGMD and unrevealing genetic testing, we preselected patients using 5 simple clinico-pathologic features and found a relatively high proportion $(n=6 / 11 ; \sim 55 \%)$ of patients with anti-HMGCR autoantibodies. These patients had a favorable response to immunosuppressive therapy. Because we preselected patients based on clinical features before autoantibody testing, we may have missed additional patients with anti-HMGCR myopathy with unexpected presentations and underestimated the overall prevalence in this cohort.

The overall clinico-pathologic presentation of these patients was indistinguishable from other patients with LGMD, including those with genetic confirmation. Illustrating this point, in the patients who tested negative for anti-HMGCR autoantibodies $(n=5 / 11)$, we subsequently found a patient with a second CAPN3 deletion mutation that was missed on the original NGS panel testing and another patient with GMPPB mutations, a gene that was not included in the NGS panel.

Analyzing an independent patient cohort with established antiHMGCR myopathy, we found an $\sim 33 \%$ prevalence for a LGMD-like presentation in these patients. The clinical features, disease course, and histopathologic findings of these patients were similar to the initial cohort (table 3 ). Thus, these patients independently corroborate the chronic, LGMD-like phenotype in a large subset of patients with anti-HMGCR myopathy. The preselection clinical criteria in the initial cohort were also found in most validation cohort patients; however, the pattern of weakness in the posterior thigh was not universally present. Thus, in future studies, less restrictive patient selection criteria may help identify additional patients.

A few criteria have been proposed to aid in establishing pathogenicity of an autoantibody (reviewed here ${ }^{19}$ ). Detecting 
anti-HMGCR autoantibodies falls short of providing definitive proof for an autoimmune disease in these patients, but our inference establishing this connection is supported by other data.

Anti-HMGCR autoantibodies are not found in healthy individuals or those with self-limited statin intolerance/myopathy. ${ }^{20}$ Most importantly, genetically proven muscular dystrophy patients do not test positive for anti-HMGCR antibodies. ${ }^{21}$ To exclude the possibility of ELISA false positives (estimated at $\sim 0.7 \%$ ), ${ }^{20}$ we confirmed the presence of anti-HMGCR autoantibodies in all the NIH LGMD-like patients using the gold standard immunoprecipitation assay. Similarly, the French anti-HMGCR cohort was tested using either a validated ELISA or ALBIA test.

CK levels are closely associated with disease activity in antiHMGCR myopathy, ${ }^{10,22}$ and all treated patients in our study showed unequivocal improvement in CK levels (tables 2 and 3). This was the case even in those patients never treated with steroids because steroids can result in nonspecific CK reduction irrespective of disease etiology. Notably, the very few patients in the validation cohort who did not pursue treatment had persistently elevated CK levels. Most treated patients also had functional gains or improvement on manual muscle strength testing and/or MRI STIR signal intensity (table 2 and figure 1, D). These improvements were most notable in those with shorter duration of disease who received immunotherapy within 4 years of symptom onset. The stabilization and/or improvements documented in these patients would be counter to the natural history of nearly all known LGMDs, especially in patients with greater than 1 year of follow-up. In parallel, the partial relapse of P1 after lengthening of IVIg interval and his subsequent improvement after return to the previous dosing interval also suggest a treatment response directly attributable to immunotherapy.

The frequency of 2 immunogenetic alleles, HLA-DRB1*11:01 and 07:01, is increased in adult and pediatric patients with subacute onset anti-HMGCR myopathy, respectively. ${ }^{7,16,17}$ In the NIH cohort that was systematically tested for these HLA subtypes, all but 1 patient had either the HLA-DRB1*11:01 or 07:01 allele, which is much higher than what would be expected in the general population, providing further support for anti-HMGCR myopathy with a distinct phenotype in these patients.

It is conceptually possible that anti-HMGCR myopathy can co-occur with a genetic muscular dystrophy or even be triggered by it. The NIH anti-HMGCR-positive patients underwent extensive genetic testing by NGS panels $(n=6)$, WES $(n=4)$ and/or WGS $(n=1)$. The Salpêtrière validation cohort patients had less extensive but more directed molecular and genetic testing. Although these genetic tests were unrevealing, we cannot exclude this possibility in our cohort with absolute certainty, in part because of the limitations of current sequencing technologies; however, our findings make this possibility doubtful.
Our findings on muscle imaging suggest that without treatment, fatty replacement of muscle increases as the disease progresses, limiting the opportunity of a clinical response to treatment in later stages. There are very few reports about treatment of patients with unexplained hyperCKemia and anti-HMGCR myopathy ${ }^{23}$; however, it can be hypothesized that initiating immunotherapy during this stage may have the potential of preventing the clinical manifestations of the disease and require less aggressive immunosuppressive regimens. In our experience, regardless of disease duration, immunotherapy still provided a tangible benefit and, at the very least, seems to have prevented a further decline in motor function in patients with LGMD-like anti-HMGCR myopathy. Nonetheless, given the small number of patients and the observational nature of our study, treatment decisions should be individualized until more conclusive, prospective, and controlled studies are conducted. Long-term follow-up of patients is necessary to evaluate the possibility and timing of weaning or discontinuing immunosuppression in this patient population.

We propose testing for anti-HMGCR autoantibodies as part of the evaluation of all patients with suspected LGMD with unrevealing genetic testing or those with asymptomatic hyperCKemia without a family history. If the diagnosis of antiHMGCR myopathy is serologically confirmed, treatment with immunosuppressant therapies should be considered.

\section{Author contributions}

P. Mohassel: data acquisition, drafting/revising the manuscript, study concept or design, analysis or interpretation of data, accepts responsibility for conduct of research and will give final approval, acquisition of data. O. Landon-Cardinal: acquisition of data, data acquisition, drafting/revising the manuscript, analysis or interpretation of data, accepts responsibility for conduct of research and will give final approval. A.R. Foley: data acquisition, drafting/revising the manuscript, study concept or design, analysis or interpretation of data, acquisition of data, study supervision. S. Donkervoort: drafting/ revising the manuscript, analysis or interpretation of data, contribution of vital reagents/tools/patients. K.S. Pak: No duplicate publication, analysis or interpretation of data, acquisition of data. C. Wahl: data acquisition, acquisition of data, study supervision. R.T. Shebert and A. Harper: data acquisition, drafting/revising the manuscript, acquisition of data. P. Fequiere: analysis or interpretation of data, drafting/revising the manuscript, acquisition of data. M. Meriggioli: data acquisition, drafting/revising the manuscript. C. Toro: data acquisition. D. Drachman: no duplicate publication, drafting/revising the manuscript, acquisition of data. Y. Allenbach: drafting/revising the manuscript, analysis or interpretation of data, acquisition of data. O. Benveniste: data acquisition, drafting/revising the manuscript, analysis or interpretation of data, acquisition of data. A. Béhin: drafting/ revising the manuscript, acquisition of data. B. Eymard: data acquisition, accepts responsibility for conduct of research and will give final approval, study supervision, principal investigator/ guarantor: Yes. P. Laforet: data acquisition. T. Stojkovic: analysis 
or interpretation of data, accepts responsibility for conduct of research and will give final approval, acquisition of data, principal investigator/guarantor: Yes. A.L. Mammen: drafting/revising the manuscript, study concept or design, accepts responsibility for conduct of research and will give final approval, acquisition of data. Dr. Bönnemann: Data acquisition, Drafting/revising the manuscript, Study concept or design, Analysis or interpretation of data, Contribution of vital reagents/tools/patients, Acquisition of data, Statistical analysis, Study supervision, Obtaining funding, Principal investigator/guarantor: Yes.

\section{Acknowledgment}

The authors thank the patients and their families for participating in our research study and Christopher Mendoza and Gilberto ("Mike") Averion for their help in the clinic. The authors also thank the NIH Intramural Sequencing Center for performing the exome sequencing; the Exome Aggregation Consortium; and the groups that provided exome variant data for comparison. A full list of contributing groups can be found at exac.broadinstitute.org/about.

\section{Study funding}

The work in C.G. Bönnemann's laboratory is supported by intramural funds of NINDS/NIH. Exome sequencing was funded through the Clinical Center Genomics Opportunity (CCGO), which is sponsored by the National Human Genome Research Institute (NHGRI), the NIH Deputy Director for Intramural Research, and the NIH Clinical Center. The NIH Undiagnosed Diseases Program is supported by the Intramural Research Program of the NHGRI and the Common Fund, Office of the Director, NIH. The work in A.L. Mammen's laboratory is supported by intramural funds of NIAMS/NIH.

\section{Disclosure}

P. Mohassel received research support from the NIH and NINDS. O. Landon-Cardinal received research support from AbbVie and Visithan Khy. A.R. Foley received travel funding from a nonprofit patient organization. S. Donkervoort, K.S. Pak, and C. Wahl report no disclosures. R.T. Shebert previously served on the Grifols Spekaers Bureau and has been an expert witness. A. Harper served on the scientific advisory board of AveXis; received travel funding from TRiNDS/NS Pharma, Italafarmaco, and Reveragen; and was a speaker for the Jett Foundation; VCU Peds at the Beach Conference (received travel funding), VCU/CHOR MDA Clinic (received travel funding); received research support from Revergan, Italfarmaco, NS Pharma, Sarepta, Lilly USA, NIH/ NIAMS/Children's Research Institute, Supporting Play Exploration and Early Development Intervention (SPEEDI) grant, Neuromuscular Research Network, and the Children's Hospital Foundation. P. Fequiere reports no disclosures. M. Meriggioli served on the scientific advisory board of Novartis and is employed by AveXis/Novartis. C. Toro, D. Drachman, and Y. Allenback report no disclosures. $O$. Benveniste served on the scientific advisory board of CSL Behring, Novartis, and LFB; received travel funding from CSL Behring and LFB; consulted for Novartis, CSL Behring, and Neovacs; and received research support from LFB, Novartis, Shite, CSL Behring, Neovacs, DGOS/INSERM, PHRC, AFM, and The Myositis Association. A. Béhin served on the scientific advisory board of Ultragenyx and Genzyme; and received travel funding and/ or speaker honoraria from Ultragenyx and Toulouse; B. Eymard received travel funding and/or speaker honoraria from LFG, Biogen, and BioMarin; consulted for Sarepta; and received research support from AFM-Telethon. P. Lafôret served on the advisory board of Genzyme-Sanofi Pompe; received travel funding and speaker honoraria from GenzymeSanofi and Spark Therapeutics; and received research support from Genzyme-Sanofi, Valerion, and the French Glycogenosis Association. T. Stojkovic served on the scientific advisory board of Ultragenyx and received honoraria from the laboratory. A.L. Mammen served on the editorial board of Experimental Neurology and Arthritis and Rheumatism; holds a patent for a commercial test for anti-HMGCR antibodies that is licensed to INOVA diagnostics; received research support from NIAMS/NIH; is a board member of The Myositis Association; and his spouse received research support from NIDDK/ NIH. C.G. Bönnemann served on the scientific advisory board of Cure CMD, the RYR1 Foundation, Audentes, Abeona, WAVE Therapeutics, and Solid Therapeutics; received travel funding not funded by the industry; is co-editor-in-chief for the Journal of Neuromuscular Disease; served on the editorial board of Matrix Biology, Annals of Neurology, and the Journal Muscle Research and Cell Motility; holds a patent for diagnosing COL6-related disorders and methods for treating same diagnosis and exon skipping technology for a deep intronic pseudo exon mutation in COL6a1; and received research support from Santhera, Audentes, and NIH. Full disclosure form information provided by the authors is available with the full text of this article at Neurology.org/NN.

\section{Publication history}

Received by Neurology: Neuroimmunology \& Neuroinflammation May 30, 2018. Accepted in final form October 16, 2018.

\section{References}

1. Thompson R, Straub V. Limb-girdle muscular dystrophies-international collaborations for translational research. Nat Rev Neurol 2016;12:294-309.

2. Benveniste O, Romero NB. Myositis or dystrophy? Traps and pitfalls. Presse Med 2011;40:e249-e255.

3. Christopher-Stine L, Casciola-Rosen LA, Hong G, Chung T, Corse AM, Mammen AL. A novel autoantibody recognizing $200-\mathrm{kd}$ and $100-\mathrm{kd}$ proteins is associated with an immune-mediated necrotizing myopathy. Arthritis Rheum 2010;62: 2757-2766.

4. Mammen AL, Chung T, Christopher-Stine L, et al. Autoantibodies against 3-hydroxy3-methylglutaryl-coenzyme A reductase in patients with statin-associated autoimmune myopathy. Arthritis Rheum 2011;63:713-721.

5. Tard C, Tiffreau V, Jaillette E, et al. Anti-HMGCR antibody-related necrotizing autoimmune myopathy mimicking muscular dystrophy. Neuropediatrics 2017;48: 473-476.

6. Mohassel P, Foley AR, Donkervoort S, et al. Anti-3-hydroxy-3-methylglutaryl-coenzyme a reductase necrotizing myopathy masquerading as a muscular dystrophy in a child. Muscle Nerve 2017;56:1177-1181.

7. Kishi T, Rider LG, Pak K, et al. Association of anti-3-hydroxy-3-methylglutaryl-coenzyme a reductase autoantibodies with $\mathrm{DRB} 1^{*} 07: 01$ and severe myositis in juvenile myositis patients. Arthritis Care Res (Hoboken) 2017;69:1088-1094.

8. Tansley SL, Simou S, Shaddick G, et al. Autoantibodies in juvenile-onset myositis: their diagnostic value and associated clinical phenotype in a large UK cohort. J Autoimmun 2017;84:55-64.

9. Liang WC, Uruha A, Suzuki S, et al. Pediatric necrotizing myopathy associated with anti-3-hydroxy-3-methylglutaryl-coenzyme A reductase antibodies. Rheumatology (Oxford) 2017;56:287-293. 
10. Allenbach Y, Drouot L, Rigolet A, et al. Anti-HMGCR autoantibodies in European patients with autoimmune necrotizing myopathies: inconstant exposure to statin. Medicine 2014;93:150-157.

11. Alshehri A, Choksi R, Bucelli R, Pestronk A. Myopathy with anti-HMGCR antibodies: perimysium and myofiber pathology. Neurol Neuroimmunol Neuroinflamm 2015;2: e124.

12. Allenbach $Y$, Mammen AL, Stenzel W, Benveniste O. Immune-Mediated Necrotizing Myopathies Working Group. 224th ENMC international workshop:: clinico-seropathological classification of immune-mediated necrotizing myopathies Zandvoort, The Netherlands, 14-16 October 2016. Neuromuscul Disord 2018;28:87-99.

13. Pinal-Fernandez I, Casal-Dominguez M, Carrino JA, et al. Thigh muscle MRI in immune-mediated necrotising myopathy: extensive oedema, early muscle damage and role of anti-SRP autoantibodies as a marker of severity. Ann Rheum Dis 2017;76: 681-687.

14. Waters MJ, Limaye V. Clinico-serologic features of statin-induced necrotising autoimmune myopathy in a single-centre cohort. Clin Rheumatol 2017;37:543-547.

15. Drouot L, Allenbach Y, Jouen F, et al. Exploring necrotizing autoimmune myopathies with a novel immunoassay for anti-3-hydroxy-3-methyl-glutaryl-CoA reductase autoantibodies. Arthritis Res Ther 2014;16:R39.

16. Mammen AL, Gaudet D, Brisson D, et al. Increased frequency of DRB1*11:01 in antihydroxymethylglutaryl-coenzyme A reductase-associated autoimmune myopathy. Arthritis Care Res (Hoboken) 2012;64:1233-1237.
17. Ohnuki Y, Suzuki S, Shiina T, et al. HLA-DRB1 alleles in immune-mediated necrotizing myopathy. Neurology 2016;87:1954-1955.

18. Mazzone ES, Coratti G, Sormani MP, et al. Timed rise from floor as a predictor of disease progression in Duchenne muscular dystrophy: an observational study. PLoS One 2016;11:e0151445.

19. Drachman DB. Autonomic "myasthenia": the case for an autoimmune pathogenesis. J Clin Invest 2003;111:797-799.

20. Mammen AL, Pak K, Williams EK, et al. Rarity of anti-3-hydroxy-3-methylglutarylcoenzyme A reductase antibodies in statin users, including those with self-limited musculoskeletal side effects. Arthritis Care Res (Hoboken) 2012;64:269-272.

21. Mammen AL, Casciola-Rosen L, Christopher-Stine L, Lloyd TE, Wagner KR. Myositis-specific autoantibodies are specific for myositis compared to genetic muscle disease. Neurol Neuroimmunol Neuroinflamm 2015;2:e172. doi: 10.1212/ NXI.0000000000000172.

22. Werner JL, Christopher-Stine L, Ghazarian SR, et al. Antibody levels correlate with creatine kinase levels and strength in anti-3-hydroxy-3-methylglutarylcoenzyme A reductase-associated autoimmune myopathy. Arthritis Rheum 2012;64 4087-4093.

23. Troyanov Y, Landon-Cardinal O, Fritzler MJ, et al. Atorvastatin-induced necrotizing autoimmune myositis: an emerging dominant entity in patients with autoimmune myositis presenting with a pure polymyositis phenotype. Medicine 2017; 96:e5694. 


\section{Neurology \\ Neuroimmunology \& Neuroinflammation}

\section{Anti-HMGCR myopathy may resemble limb-girdle muscular dystrophy}

Payam Mohassel, Océane Landon-Cardinal, A. Reghan Foley, et al.

Neurol Neuroimmunol Neuroinflamm 2019;6;

DOI 10.1212/NXI.0000000000000523

This information is current as of December 12, 2018

\section{Updated Information \& Services}

References

Subspecialty Collections

Permissions \& Licensing

Reprints including high resolution figures, can be found at:

http://nn.neurology.org/content/6/1/e523.full.html

This article cites 23 articles, 1 of which you can access for free at: http://nn.neurology.org/content/6/1/e523.full.html\#\#ref-list-1

This article, along with others on similar topics, appears in the following collection(s):

Autoimmune diseases

http://nn.neurology.org//cgi/collection/autoimmune_diseases

MRI

http://nn.neurology.org//cgi/collection/mri

Muscle disease

http://nn.neurology.org//cgi/collection/muscle_disease

Ultrasound

http://nn.neurology.org//cgi/collection/ultrasound

Information about reproducing this article in parts (figures,tables) or in its entirety can be found online at:

http://nn.neurology.org/misc/about.xhtml\#permissions

Information about ordering reprints can be found online:

http://nn.neurology.org/misc/addir.xhtml\#reprintsus

Neurol Neuroimmunol Neuroinflamm is an official journal of the American Academy of Neurology.

Published since April 2014, it is an open-access, online-only, continuous publication journal. Copyright

Copyright $\left({ }^{\circ} 2018\right.$ The Author(s). Published by Wolters Kluwer Health, Inc. on behalf of the American

Academy of Neurology.. All rights reserved. Online ISSN: 2332-7812.

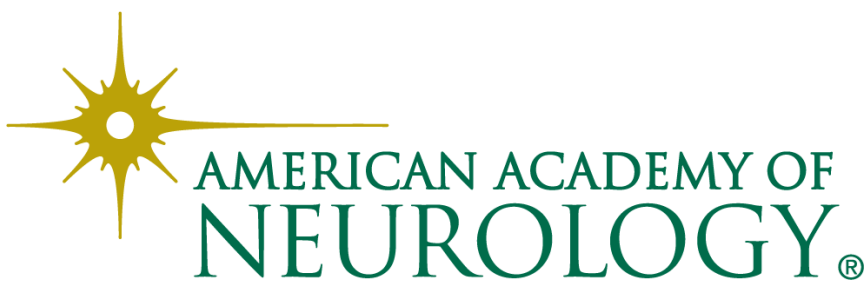

